\title{
The Empirical Analysis on the Customs' Impact on Divorce Based on Multiple Regression Analysis Models
}

\author{
Meng Wang \\ College of Foreign Languages, Dalian Jiaotong University, Dalian, China \\ w_ang_meng@126.com
}

Keywords: Multiple regression analysis; Mathematical physics equations; Empirical analysis; Statistical analysis; Trend prediction

\begin{abstract}
With the rapid development of Japanese economy, the stale marriage customs in history already can not adapt to the longing for the freedom of marriage of young men and women, free love gradually replaced the arranged marriage. Although the diversification of marriage marks great development of democratization of Japan, it also causes a significant increase of the divorce rate. Now the marital status of the Japanese society is going through the biggest unrest; the phenomenon of narita divorce and late-life divorce has become the most sensitive problem of Japanese society. This paper established the multiple regression analysis model of late-life divorce to analyze and study the influence of Japanese marriage custom on late-life divorce. Through the analysis it can effectively provide suggestions for the development direction of the marriage in Japanese society, and then it also provides the theory reference and guiding basis to reduce the divorce rate, stabilize the family and society.
\end{abstract}

\section{Introduction}

Japan is a developed capitalist country, at the same time it is also a traditional eastern country that deeply influenced by the confucianism, and it has the concept of the traditional ideology in the marriage problems[1]. However, the divorce rate in Japan has gradually increased since the 1990s, and it is even more than some western developed capitalist countries. The increasing divorce phenomenon is not only reflected in the rising divorce rate, but also comes with the characteristics of high age and female-dominated situation and so on. The change of marriage concept in Japan also brought a serious social problem, and it is the rising social divorce rate and the late-life divorce is particularly remarkable. The female divorcee enumerated the reasons such as "domestic violence", "extramarital affairs", and "don't give living expenses" and so on; the male divorcee listed reasons such as "extramarital affairs", "the fraught relationship between mother-in-law and daughter-in-law" and so on[2]. It is compared with the before situation, the proportion of the divorce reason of "extramarital affairs" has declined. After the divorce, the main difficulty of the women is the "work" and "economy"; and the main difficulty of the men is "household" and "remarriage". The direct consequence of the rising divorce rate is the increase of "single parent families" in Japanese society, and this is bound to increase the new financial burden of the society and the government.

\section{Japanese marriage customs and triggered marriage problems}

\section{A. The custom of samurai family status}

During the edo period, Japan once coexisted with two kinds of different marriages: one is the marriage that represented by the samurai family status and arranged and agreed by the parents and relatives, the well matched marriage was formed because the samurai wanted to protect the lineage and safeguard the family status and their own interests.Essentially, two methods of the marriages both were the arranged marriage by the parents and relatives[3]. This kind of marriage depended on the Japanese meiji government's basic national policy that the whole Japan was looked as a family and the emperor was the parent, whether the married men and women had love and their characters were match was not important, only in the situation of having equal wealth and family status with the marriage partners, they could smoothly get the approval of their parents and families. 
B. The propagation and impact of the concept of modern marriage

Until 1945, after the end of the World War II, the Japanese government amended the civil law and marriage law, the form of marriage had changed dramatically, the former arranged marriage began to change for the free love marriage. In the free love marriage, free premarital contact was the indispensable condition. In this free love marriage the traditional concept of the combination of family and family was continuously weakened, the opportunity of men and women to know and understand each other was increasing, and all these had influence on the traditional culture and customs in Japan.

In recent years, Japan begins to appear the phenomenon of never married celibates, the tendency of late marriage and voluntary childlessness and so on[4]. The pressure of marriage seems to be on the decline, variety of views on marriage in Japanese society begins to develop, and these aspects such as pay more attention to the family, respect personal will, equality between men and women and individual freedom are in the position of having priority of the new generation of the marriage concept. Its reason mainly is the rapid development of Japanese economic, the invasion of the western personality, socialism democratic values gradually breaks the traditional marriage concept, this makes the young men and women dare to get rid of the parents' control, have their own independent consciousness and have the free love, independent marriage according to their own will. The traditional marriage concept of carrying on the family line and the interests of the family has ceased to exist.

C. The changes and conflicts of marriage relationship

The social gender positioning of "men go out and women stay home" of the traditional concept long occupied the people's minds. Such as "Gender role division of labor" in the early industrialization of Japan, the physiological characteristics of female fertility, breast-feeding and the family role made the women have to leave their jobs and go home to have housework and take care of their children, the wife was called "the rear guard" and took charge of the housework[5]. The changes and conflicts of marriage relationship demonstrate that the traditional male status are suffering inversion, but they also indicate the changing trends of Japanese society marriage in the 21 st century.

\section{Perspective analysis on the late-life divorce phenomenon}

"Late-life divorce" refers to the divorce of middle and old aged couples that have married for 20 years, and it reflects a special phenomenon happened in Japanese society. Particularity lies in the law of development in accordance with the general relationship between husband and wife, if the marriage lasts more than 20 years or 30 years, then the marriage comes into the relative "marriage stationary phase". But now Japan is experiencing the biggest unrest of the social marital status after the war, according to the dynamic statistics of the labor population in Housheng province of Japan, the divorce of the couples that have married 20 years of couples is called "late-life" divorce, and the number of this kind of divorce cases in Japan had reached to 11000 in 1980, and it shot up to 45000 pieces in 2002.

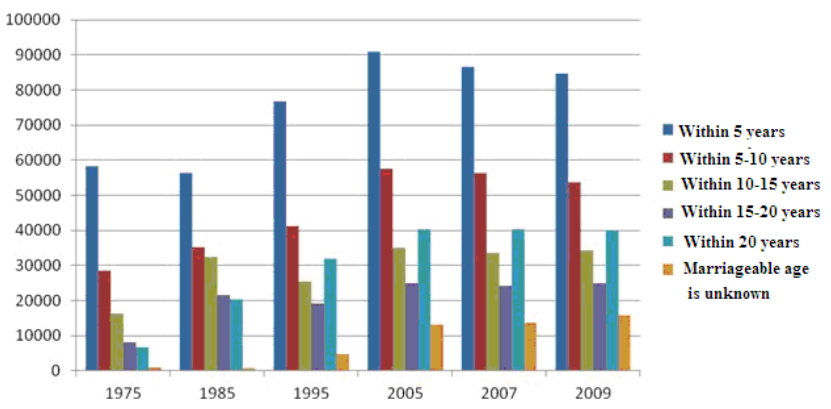

Figure 1. The digital chart of divorces at different marriage ages

Table 1 and Figure 1 show that the phenomenon of late-life divorce was not common in the middle of the $1970 \mathrm{~s}$, and it only accounted for $5.72 \%$ of the total number of divorce[6]. In 1985, the proportion of late-life divorce increased to $12.26 \%$, but it still was the lowest in the divorce crowd. In the $1990 \mathrm{~s}$, the situation had subtle change, and the late-life divorce rate significantly rose in the 
relatively steady total divorce rate. In 1995, the marriage age of the late-life divorce was more than the age section from 10 years to 20 years. In 2007, there had 40353 couples that experienced the latelife divorce, it was 6.89 times more than the total number in 1975, and it become the largest group of divorce that the marriage age was less than 10 years.

TABLE I. The digital statistic table of divorces at different marriage ages

\begin{tabular}{|c|l|l|l|l|l|c|}
\hline & $\mathbf{1 9 7 5}$ & $\mathbf{1 9 8 5}$ & $\mathbf{1 9 9 5}$ & $\mathbf{2 0 0 5}$ & $\mathbf{2 0 0 7}$ & $\mathbf{2 0 0 9}$ \\
\hline Within 5 years & 58336 & 56422 & 76710 & 90899 & 86607 & 84691 \\
\hline Within 5-10 years & 28597 & 35338 & 41185 & 57564 & 56335 & 53663 \\
\hline Within 10-15 years & 16206 & 32310 & 25308 & 35097 & 33693 & 34189 \\
\hline Within 15-20 years & 8172 & 21528 & 19153 & 24887 & 24166 & 24992 \\
\hline Within 20 years & 6810 & 20434 & 31877 & 40395 & 40353 & 40106 \\
\hline Marriageable age is unknown & 1014 & 608 & 4783 & 13075 & 13678 & 15767 \\
\hline
\end{tabular}

The lack of communication of the Middle-aged couple, and the indifferent feeling is the chief reason of late-life divorce, the affection become the only counterweight to maintain the marriage, when the couple comes into the exhaustion period, then it appears "late-life crisis". The word of "late-life crisis" comes from Japan, it refers to the ethnic group that the age is between 45 years and 64 years, they have the ability of independent consumption and dare to pursue the fresh things and fashion, but at the same time they are facing the problems or crisis such as the work, retirement, body health, family marriage, sex life and so on. The "late-life crisis" will bring the "late-life divorce".

Through the modification of the marriage law, on April 1, 2008 it started to stipulate the segmentation system of the pension, when the couples determine to divorce the wife can get half of her husband's pension. Because during their work, the Japanese must submit a certain number of pensions every year, and when they retire at the age of 63, the government will return it to the person every month in accordance to a certain amount[7]. If the wife gets her husband's pension, it means that the wife has a fixed income every month and she will have no trouble in the life. Therefore, after the implementation of this system, the phenomenon of the late-life divorce significantly increased, and the $95 \%$ of the divorces were put forward by the woman.

\section{The multiple regression analysis model of the influence of Japanese marriage customs on the late-life divorce}

A. The preliminary descriptive statistical analysis on the sample data

We can use the DESCRIPTIVES options of $F$ in SUMMMARIZE menu item of the SPSS software to have analysis, and the descriptive statistics are shown in Table 2. But from the Table 2 of the descriptive statistics the relationship between the variables can't be seen very clearly, it still needs further analysis, but the statistics show that the differences of the range of these variables' values are bigger, therefore in the following analysis process we should consider having the standardized processing of the variables[8].

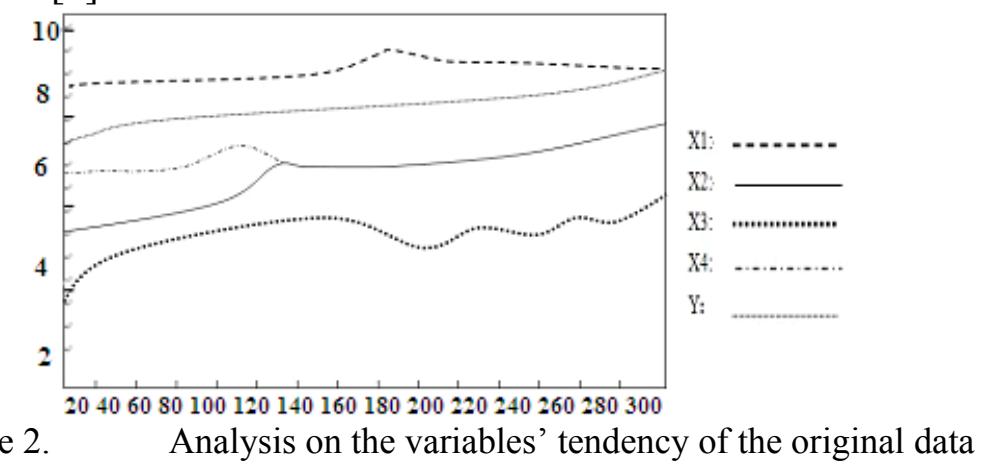

B. Analysis on the variables' tendency of the original data

Based on the differences of the own level of the variable and the unit of measurement, firstly it should have standardized processing of the data, and take the natural logarithm of the variable to have standardization. the $\mathrm{X}$ axis represents the sample, $\mathrm{Y}$ axis represents the standardized variable of the late-life divorce digital, in the operation of the SPSS software, we can know that the trends of the variables are basically consistent, but curve fluctuation of $X_{3}$ variable is bigger[9]. Because its value is relatively small, it is reserved and the specific circumstances are shown in Figure 2. 
From the Figure 2 we can know that the relationship between the variables is basically the linear relationship, so we can build the multiple linear regression equation.

C. Solution to the regression equation

Linear regression analysis in SPSS software provides four kinds of regression analysis method, and they are the method of one entry, the method of stepwise regression, the method of forward entry, and the method of backward rejection. The principles of four methods are different, but the conclusion will normally be the same. Therefore, we use the simplest method of one entry to have the regression analysis on the sample data in Table 2.

The mean value is the most important measured value of the central tendency of the data. If the data is unstructured, it can use the following formula to calculate its value[10]:

$$
\vec{X}=\frac{X_{1}+X_{2}+\cdots X_{n}}{n}=\frac{\sum_{i=1}^{n} X_{i}}{n}
$$

Variance is the average value of the dispersion square, and it is the $\sigma^{2}=\frac{\sum_{i=1}^{N}\left(X_{i}-u\right)^{2}}{N}$, the standard deviation is the positive square root of the variance, and it is the following formula[11]:

$$
\cdot \sigma=\sqrt{\frac{\sum_{i=1}^{N}\left(X_{i}-u\right)^{2}}{N}} \quad \sigma=\sqrt{\frac{\sum_{i=1}^{M}\left(X_{i}-u\right)^{2} f_{i}}{\sum_{i=1}^{M} f_{i}}}
$$

Significant level is determined according to the risks of the refused interval, it should be different according to the nature of the research questions and requirements of conclusions accuracy, and we often use the value of $0.1,0.05,0.01$, and 0.001 of the significance level[12]. The Litho poll uses the significance level of 0.1 , the inspection of other social phenomena uses the level of 0.05 , and the engineering test uses the level of 0.001 . The significance level is higher, and the risk of wrong judgment of the significant difference is greater.

In a certain period of time, the phenomenon of late-life divorce is affected by many factors, such as the distribution of property issues brought by the pension policy, the change of concept of the marriage, family conflicts, asexual marriage. Therefore these four variables are as the explanatory variables and we can have analysis of their influence on the late-life divorce.

Table 2 shows three descriptive statistics information of the five variables, and they include the standard deviation, the mean value and the number of samples.

\begin{tabular}{|l|l|l|l|l|l|}
\hline \multicolumn{1}{|c|}{ TABLE II. The basic information of the investigation on the late-life divorce } \\
\hline Variable $\mathbf{X}$ & $\begin{array}{c}\text { The number } \\
\text { of samples N }\end{array}$ & $\begin{array}{c}\text { Mean } \\
\text { value }\end{array}$ & Standard deviation & $\begin{array}{c}\text { The } \\
\text { minimum }\end{array}$ & $\begin{array}{c}\text { The } \\
\text { maximum }\end{array}$ \\
\hline Change of marriage concept $X_{1}$ & 300 & 26.1 & 4.68 & 12 & 40 \\
\hline Property issues $X_{2}$ & 300 & 35.26 & 3.82 & 20 & 48 \\
\hline Family conflict $X_{3} X_{4}$ & 300 & 21.73 & 6.69 & 6 & 40 \\
\hline Asexual marriage & 300 & 18.32 & 3.45 & 7 & 79 \\
\hline Marriage Satisfaction & 300 & 28.53 & 6.1 & 12 & 43 \\
\hline
\end{tabular}

The sampling distribution of the sample's mean value is ${ }_{X \sim N\left(u, \frac{\sigma^{2}}{n}\right)}$, and there has ${ }_{Z}=\frac{\vec{x}-u}{\sigma / \sqrt{n}} \sim N(0,1)$. For the significant level $\alpha$, we can make $P\left(-Z_{\frac{\alpha}{2}}<Z<Z_{\frac{\alpha}{2}}\right)=1-\alpha$, and then $\left._{P\left(\mathcal{x}-Z_{\frac{\alpha}{2}}\right.} \cdot \frac{\sigma}{\sqrt{n}}<u<\vec{x}+Z_{\frac{\alpha}{2}} \cdot \frac{\sigma}{\sqrt{n}}\right)=1-\alpha$, so the confidence interval is: $\left(\neg-Z_{\frac{\alpha}{2}} \cdot \frac{\sigma}{\sqrt{n}}, \mathcal{\imath}+Z_{\frac{\alpha}{2}} \cdot \frac{\sigma}{\sqrt{n}}\right)$.

The results showed that all the variables were at once joined to the regression equation to have the inspection, it revealed that although the test value and the coefficient of determination and other statistics of the regression equation reached to the regression test standard, but $X_{3} 、 X_{4}$ these two vectors did not pass the $t$ test, therefore we will have to adjust the regression equation. It should explain that the $95 \%$ confidence standard is used here to have the inspection, if for a variable, its null hypothesis possibility level of the regression coefficient reaches more than $5 \%$, and the variable will be deleted from the equations. In this regression equation, the null hypothesis possibility level of the 
regression coefficient of $X_{3}$ and $X_{4}$ were 0.013 and 0.602 , they were both more than 0.05 , so they couldn't be kept in the equation, and they were rejected in turn. So the property issues and the change of marriage concept are the main factors that lead to the late-life divorce, the family conflicts and asexual marriage are the secondary factors. Then, we can observe the actual value of the dependent variable and the predictive value from the regression equation to find that the fitting effect of regression equation is very good. In the Table 1 the number of the late-life divorce in 2007 was 40,353 , and through the prediction the estimated number of divorces in 2012 will be 62,666 .

\section{Conclusion}

The marriage customs in Japan lead to the change of the concept of the modern Japan marriages and the transformation of the marriage role localization, in this situation the marital relationship between Japanese couple is gradually indifference. The centralization of social and family conflicts, the transition of pension system and asexual marriage and other problems are closely linked with the phenomenon of late-life divorce in Japan. The Japanese society wants to continuous development, it must solve the reflexivity of the modernization and the development of marital family and the incompatibility of the social progress and two genders development, and adjust the continuous oscillation and process of the relationship between the marriages in Japan. The government and nongovernmental organizations should help the men that long-term protected by the tilted social system and regulations go through the confused, and even painful role adaptation, help the divorced women solve many life difficulties, but these will increase the burden of the government and the society. Therefore, in this paper, we can use the multiple regression analysis model to have research and analysis of the influence of the marriage customs on the phenomenon of divorces, have analysis of the influence of the Japanese marriage customs on the phenomenon of late-life divorces, and have research on the root causes of the change of the marriage relationship, and then we can take positive and effective measures to have the macroeconomic regulation and control, such as the adjustment of the life parental assistance, cost of maintenance, segmentation system of the pension and so on, in this way it can guarantee the stable family mode and at the same time carry on rethinking the economic mode of the entire country.

\section{References}

[1] Wu Weiping. Discussion and revelation of the middle-aged and older Japanese divorce . Journal of Xiangtan teaching college, 2009(1):37-39

[2] Zhang Dongdong. Hot divorce and contemporary Japanese social ethical .Study on foreign problem, 2010(4):78-81

[3] Sun Xin. "Narita divorce" and "late-life divorce" -- perspective analysis on recent phenomenon of divorce in Japanese society .The society, 2012(06): 20-22

[4] Deng Guosheng. Japan's marriage crowded and consequences .Analysis on the market and demographic, 2012(5):43-45

[5] Ma Yuzhen. The change of Japanese marriage concept .Overseas fax, 2004(01)

[6] FuWuzhi. Japanese social structure .Guangdong people's publishing house, 2012:99-103

[7] YeshanJiuye. The evolution of relationship the marriage in Japanese society .Shanghai academy of social sciences, 2010:14-17

[8] Tian Xiaohong. Integration and conflict of Japanese marital relationship after the war .Shanghai academy of social sciences, 2009:19-21

[9] Lin Bihong. The view of Japanese workplace marriage women change from the film and television play . Journal of Chongqing science and technology college.2011 (11):53-56

[10] Tong Xiaowei. The formation of modern Japanese marriage concept .Journal of Shenzhen university, 2004 (5):85-88

[11] Jiang Tianxi. History and current situation of marriage customs in Japan .Journal of northwestern university.2011 (2):36-39

[12] The Japanese Prime Minister's Office. Women's status and policy .The printing office of Dazang province, 2009: 115-118 